\title{
Solid State Adaptive Rotor Using Postbuckled Precompressed, Bending-Twist Coupled Piezoelectric Actuator Elements
}

\author{
Ronald M. Barrett and Ryan Barnhart \\ Department of Aerospace Engineering, University of Kansas, 2120 Learned Hall, 1530 W 15th Street, Lawrence, \\ KS 66045-7621, USA \\ Correspondence should be addressed to Ronald M. Barrett, barrettr@ku.edu
}

Received 15 November 2011; Accepted 16 January 2012

Academic Editor: Tao Li

Copyright ( 2012 R. M. Barrett and R. Barnhart. This is an open access article distributed under the Creative Commons Attribution License, which permits unrestricted use, distribution, and reproduction in any medium, provided the original work is properly cited.

\begin{abstract}
This paper is centered on a new actuation mechanism which is integrated on a solid state rotor. This paper outlines the application of such a system via a Post-Buckled Precompression (PBP) technique at the end of a twist-active piezoelectric rotor blade actuator. The basic performance of the system is handily modeled by using laminated plate theory techniques. A dual cantilevered spring system was used to increasingly null the passive stiffness of the root actuator along the feathering axis of the rotor blade. As the precompression levels were increased, it was shown that corresponding blade pitch levels also increased. The PBP cantilever spring system was designed so as to provide a high level of stabilizing pitch-flap coupling and inherent resistance to rotor propeller moments. Experimental testing showed pitch deflections increasing from just $8^{\circ}$ peak-to-peak deflections at $650 \mathrm{~V} / \mathrm{mm}$ field strength to more than $26^{\circ}$ at the same field strength with design precompression levels. Dynamic testing showed the corner frequency of the linear system coming down from $63 \mathrm{~Hz}(3.8 / \mathrm{rev})$ to $53 \mathrm{~Hz}(3.2 / \mathrm{rev})$. Thrust coefficients manipulation levels were shown to increase from 0.01 to 0.028 with increasing precompression levels. The paper concludes with an overall assessment of the actuator design.
\end{abstract}

\section{Introduction}

For more than two decades, adaptive rotors, flaps and helicopter flight and vibration control systems have been actively pursued by a small army of technologists scattered around the world. The work of Crawley and his team at MIT in the mid-1980s laid the foundations of adaptive aerostructures by investigating the properties of bending and twist-active plates [1-3]. These early studies lead to several broad reviews which examined material properties and their associated energy and power densities when used as actuator elements $[4,5]$.

1.1. Adaptive Flaps. The earliest twist, camber, and bending active aerodynamic plates were followed by the first of the adaptive flap studies [6]. A host of adaptive flaps flowed into the technical literature at a steady rate from the early 1990s through their implementation in a full-scale rotor test bed (right) [7-19]. Through much effort it was shown that blade loads could indeed be manipulated as fast as $4 / \mathrm{rev}$ with appreciable deflection levels. However, the weight, cost, and complexity issues still prevent full transition to prototype flying aircraft and serial production aircraft. Efforts with "Smart Active Blade Tips" (SABT) showed good results, but fell prey to the same issues as conventional flaps, but with exacerbated propeller moments. Given that for every 1 unit of mass added at the $75 \%$ radius (and further out) it takes on the order of 3 units (or more) of structural mass to distribute the load into the airframe, the weight penalty alone of active flap systems is considerable. Because rotor blades are some of the most expensive items on any given rotorcraft, a sizable cost penalty because of the integration of expensive adaptive actuators is quite daunting. Still, much research regularly appears in scattered literature with new flap and actuator configurations (Figure 1).

1.2. Twist-Active Rotors. Just after the twist-active plates of Crawley, De Luis, and Lazarus were published, a series of studies were put forth on twist-active missile fins, wings, 


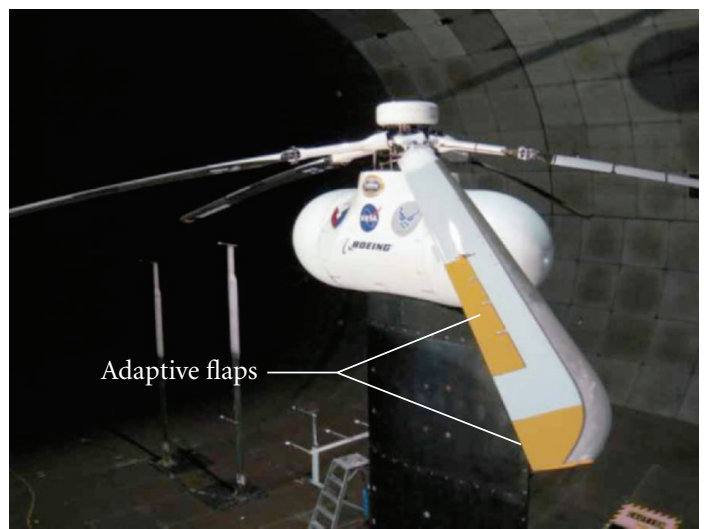

FIGURE 1: "Smart” rotor equipped with active flaps [18].

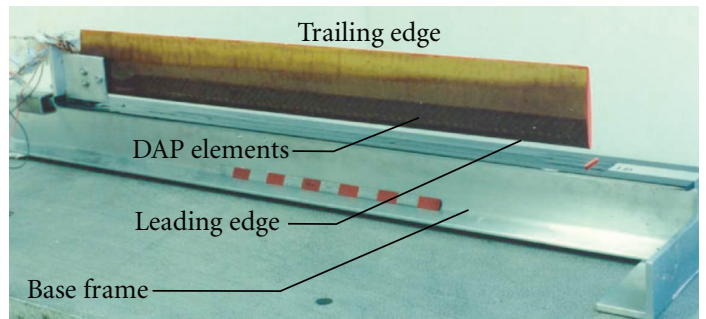

FIgURE 2: First twist-active rotor (1989) [20].

and rotor blades [20-25]. These 20+-year-old studies also included the first patent (which was also the first IP royalty-generating patent) on adaptive aerostructures to be issued. The earliest work of 1989 showed that essentially "microscopic" twist deflections could be generated [21, 22]. Clearly, these $\pm 0.2^{\circ}$ deflections were not enough for full cyclic or collective. However, they were enough to kick off the field. Twist active rotor research continued through the 1990s with expansions of the Directionally Attached Piezoelectric (DAP) elements from the first 35\% of the chord (for proper blade balance as seen in Figure 2), to much greater distances along the chord. Although destabilizing because they shift the center of gravity aft of the aerodynamic center, they did increase the \pm 0.2 degree deflections substantially to roughly $\pm 0.3^{\circ}$ at the same field strength [23]. Twist-active rotor research reached a zenith in 1999 when the largest model to date was wind tunnel tested [24]. Although largescale experimentation with twist-active rotors has come to a grinding halt, there are occasional technologists who revisit this technology [25]. As with the adaptive flap designs, the weight, cost, and complexities have been shown to be simply prohibitive.

1.3. Solid State Adaptive Rotor. One concept that was intended to skirt the "show stopping" issues associated with adaptive materials mounted on the blades was the Solid State Adaptive Rotor (SSAR) (Figure 4). This design employed DAP torque plates mounted at the root of the rotor system between the hub and the lag hinge [20, 26, 27]. Because no extra weight was added to the blade itself, the mass,
Lock number, cost, and complexity of the blade systems themselves would be no higher than conventional rotor blades. Because the actuator was designed to actively pitch the rotor about the aerodynamic center which was collocated with the line of centers of gravity and counterbalanced with Chinese weights, the only appreciable attached flow moments were inertial. Because the feathering moments were balanced, respectable pitch deflections of $8^{\circ}$ peak to peak could be commanded by the small torque plates. These considerable pitch deflections then translated into nontrivial thrust coefficient manipulation levels as seen in Figure 3. Because they were so high, eventually they were woven into the first rotorcraft to fly using adaptive aerostructures for all flight control, Gamara (Figure 5), (below).

The successes in flight test were matched by several overview papers describing the feasibility of adaptive rotors [28-31]. These overview papers described many approaches and listed several different techniques and approaches for achieving flight control. One of the later overview papers summarized not only rotorcraft, but missile, munition, and UAV successes which were numerous by 2004 [32].

1.4. VTOL Microaerial Vehicles, Ultrahigh Performance and Convertible UAVs. Given the very public successes of the SSAR program, the DoD contracted to have a subscale rotorcraft built which actually needed adaptive materials to achieve flight control on the subscale. The "Kolibri" VTOL Coleopter was commissioned by the DoD Counterdrug Technology Office to explore tunnels and stay airborne for $24 \mathrm{hrs}$ [33-37]. It was later understood that these studies were actually the very first Micro Aerial Vehicle (MAV) contracts let by the DoD. These studies eventually enabled free-flight MAVs which used piezoelectric elements extensively in their GNC packages. From 2001 through 2010 a completely new type of UAV has evolved. These new aircraft, first flown under the designation of XQ-138, is capable of hovering in more places than helicopters while pitching over (or converting) to missile mode flight to fly out at tactical missile speeds. Although major DoD elements declined funding, private sources were found and test ranges at Eglin AFB, Florida, Redstone Arsenal, AL and Fort Benning, Georgia gladly hosted the aircraft during some extreme flight tests and demos. It should also be noted that the superior performance of the aircraft also induced all competing UAV manufacturers and Government sponsors to decline all flyoff challenges and offers. The US Army's first exercise with a remote-controlled armored vehicle launching a UAV took place at Redstone Arsenal, AL when an XQ138 was launched from the turret of an FCS prototype vehicle. Eglin AFB, FL saw the first tandem flights of a Javelin Missile followed closely by an XQ-138 ultrahigh performance UAV flying a Battle Damage Assessment (BDA) mission. Parallel IFF and conversion-stalking missions were also flown for the first time in history by convertible UAVs. $40 \mathrm{~mm}$ submunitions were fired from the XQ-138 at Ft. Benning and a Mother-ship drop from $1000 \mathrm{ft}$ AGL was demonstrated. Clearly, the forefront of UAV technology is 


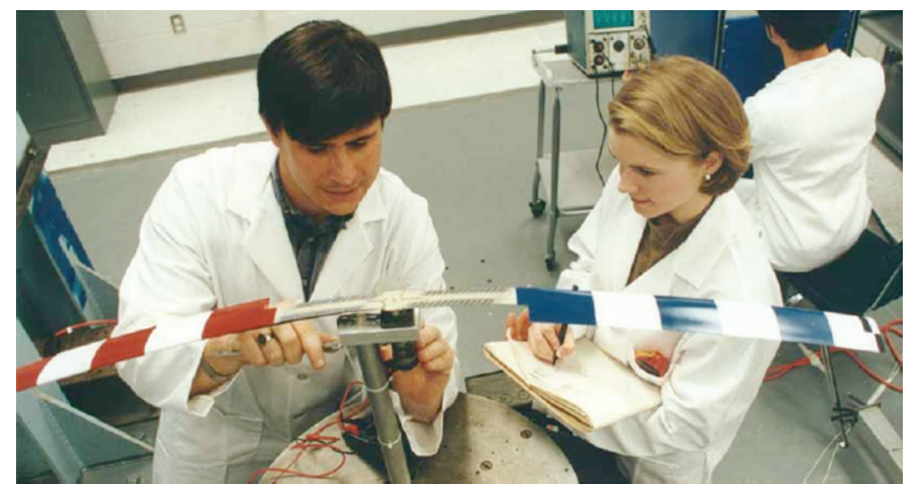

FIGURE 3: Solid state adaptive rotor (1996) [20, 26, 27].

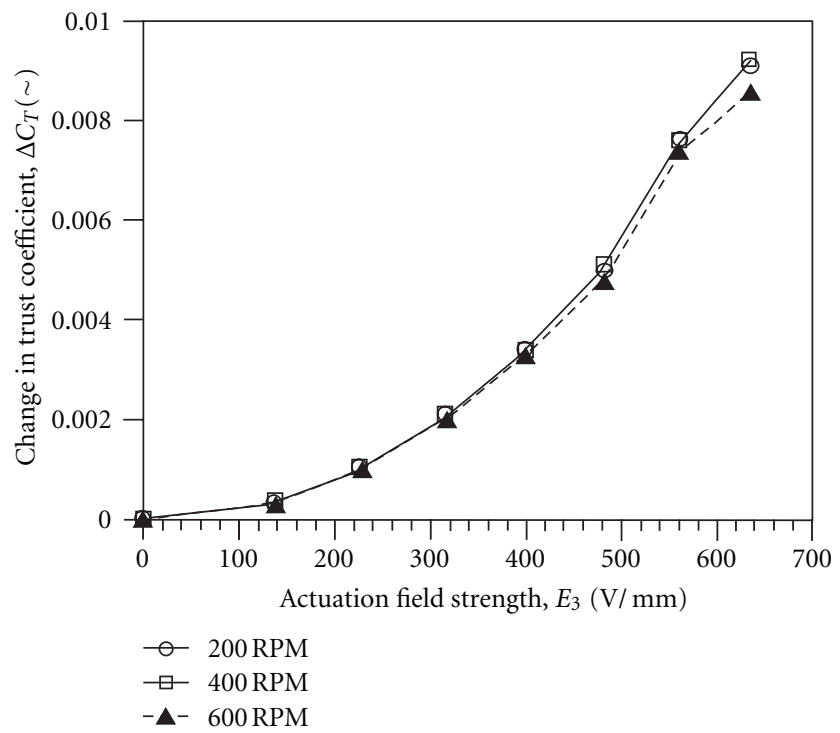

FIgURE 4: SSAR thrust coefficient change levels, $\Delta C_{T}(\sim)$.

being spearheaded by adaptive aerostructures through this class of aircraft (Figure 6).

1.5. New Discoveries in Structural Mechanics. Although flight on a $1 \mathrm{~m}$ scale was concretely demonstrated as significantly helped by adaptive aerostructures, a new branch of structural mechanics evolved from the mid-1990s through today. In 1997 the first paper describing the superior nature of a new form of structural arrangement was published [38]. Lesieutre et al. showed that by mounting a bending beam, properly the passive stiffness of the actuator, could be nulled. By nulling the passive stiffness the deflections and ultimately the electrical-to-mechanical and mechanical-toelectrical conversion efficiencies could be driven close to $100 \%$ [39]. Although Lesieutre et al. primarily used this basic discovery in electrical energy converter, the philosophy of nulling passive stiffnesses is directly transferrable to mechanical actuators. Several related studies were conducted on structures which exhibited negative stiffnesses through buckling effects associated with snap-through events [4042]. These were followed by actuator studies on bistable piezoelectric composites which used energy techniques to estimate performance [43-45]. Both the snap-through and bistable studies showed that small amounts of energy invested in piezoelectric actuators could be used to trigger much more energetic processes if the structure and surrounding materials were designed properly.

1.6. Postbuckled Precompression (Pbp) Techniques and Analysis. In 2004 a fundamental discovery was made with respect to piezoelectric actuation. The principles of piezoelectric actuation described in [38] were refined for flight control. Rather than pushing the structure through to a bistable situation, a highly controlled axial force could be used to induce a postbuckling effect. This effect would be seen to drive actuator deflections to very high values, but not sacrifice moment generation capability [46-54]. These PBP structures outperformed any other piezoelectrically driven actuators by factors of 3 and 4 . Figure 7 shows the basic arrangement of the bending version of the actuator.

Because the performance of PBP-based bending actuators is shown to be so significantly superior with respect to conventional linear techniques a new incarnation of the above model is explored in this paper. By combining the methods of using Zero-Net Passive Stiffness (ZNPS) structural design (also above), it is possible to null the passive torsional stiffness of the SSAR rotor root actuators of Figure 3. By doing so, it will be shown that otherwise huge deflections can be generated by these "old" actuators if they are just mounted properly between negative spring mechanisms.

\section{PBP SSAR Root Actuator Design}

Because PBP techniques call for more of a change in actuator design philosophy as much as a change in how adaptive actuators are handled, the rotor of Figure 3 was simply retrofitted with a pair of stiffness nulling springs so as to generate high deflections with simultaneous high moment generations. Figure 8 shows the root section following retrofit. 

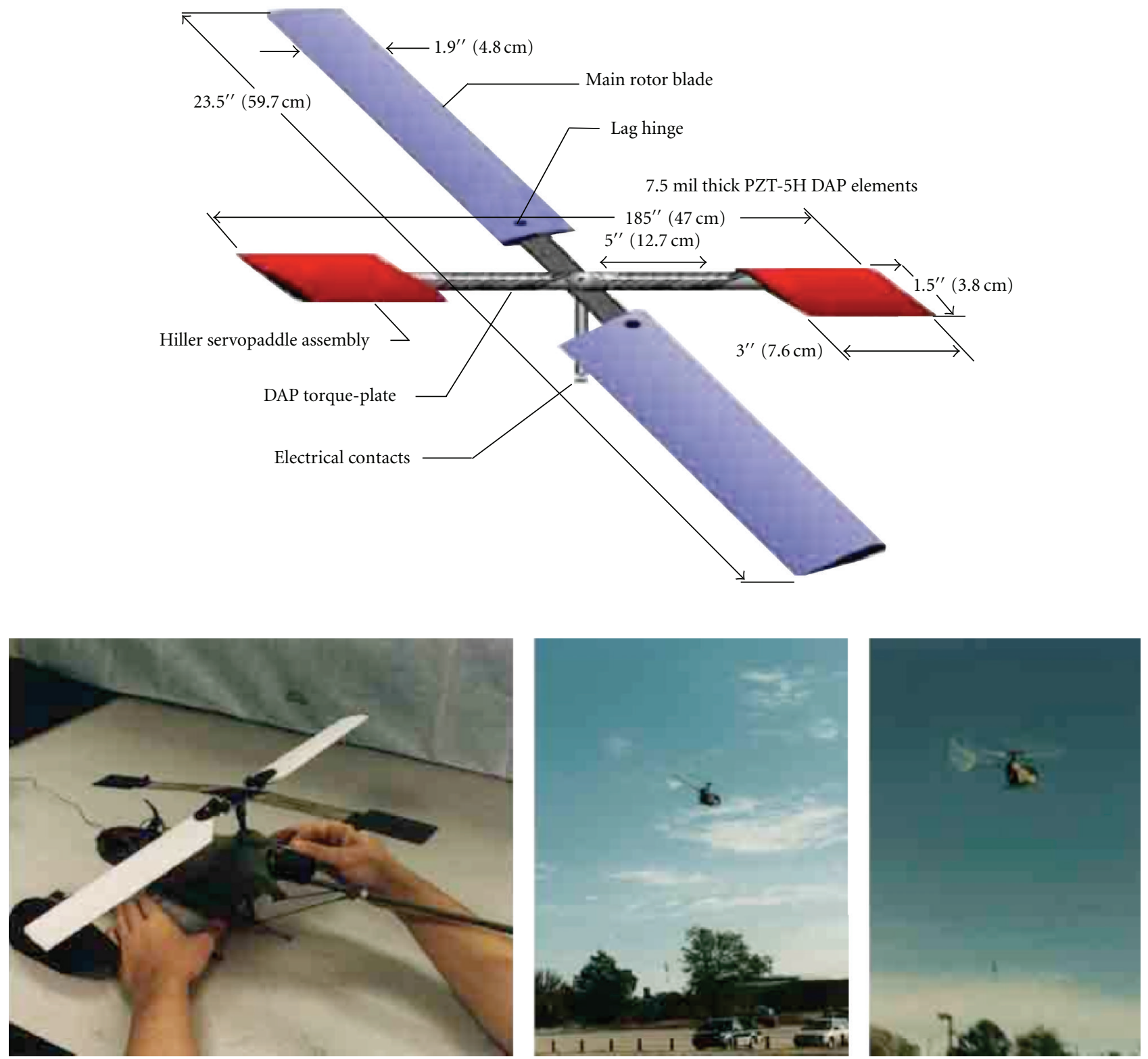

Figure 5: Gamara, the first helcopter to use adaptive materials for all flight control (1996) [27].

The spring stiffnesses and prestress levels were set by analytical modeling and fine tuning during whirl-stand testing. The analytical models called upon were established in [46-52] to determine the amount of axial forces required to fundamentally null the net passive stiffness of the pizoelectric actuator element. The overall PBP assembly design was laid out to provide several overarching properties:

(i) magnify pitch deflections without adversely affecting moment generation properties of the torque plate;

(ii) provide a stabilizing effective $\partial_{3}$ pitch-flap coupling;

(iii) balance out attached flow aerodynamic, propeller and passive torque-plate stiffnesses; (iv) not significantly impact the weight and hub drag of the assembly;

(v) allow for easy adjustment during testing to fine-tune the assembly.

The overall design takes advantage of destabilizing spring moments applied at the tip of the torque plate. Figure 9 shows the negative torsional spring arrangement. As the piezoelectric torque plate induces pitch deflections, the two springs generate a nose-up pitching moment which is structurally destabilizing, but when properly "tuned" can be balanced exactly against the passive stiffness of the torque plate laminate. By doing so, the deflections are seen to grow by factors of 3 or more while maintaining the moment resistance capability of the laminate. 


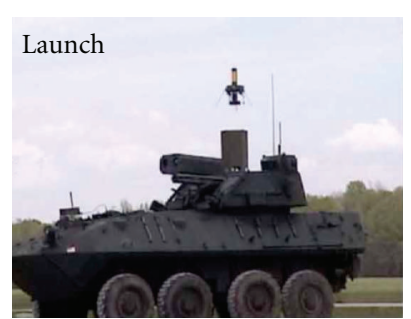

(a)

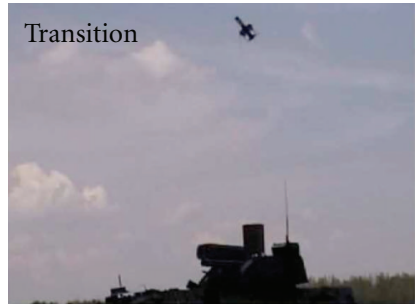

(b)

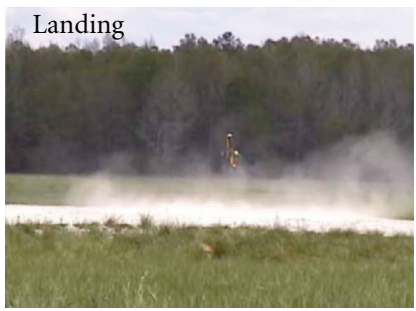

(e)

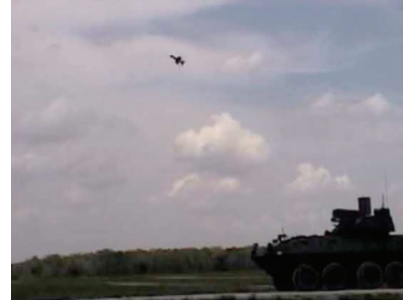

(c)

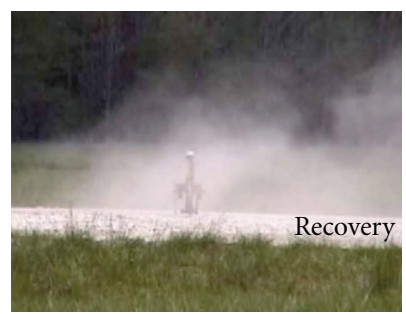

(f)

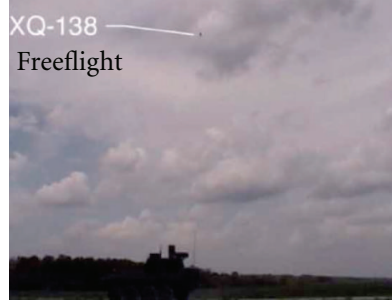

(d)

FIGURE 6: The XQ-138 ultrahigh performance UAV using piezoelectric elements in the FCS undergoing conversion to missile mode flight, Redstone Arsenal, AL [55].

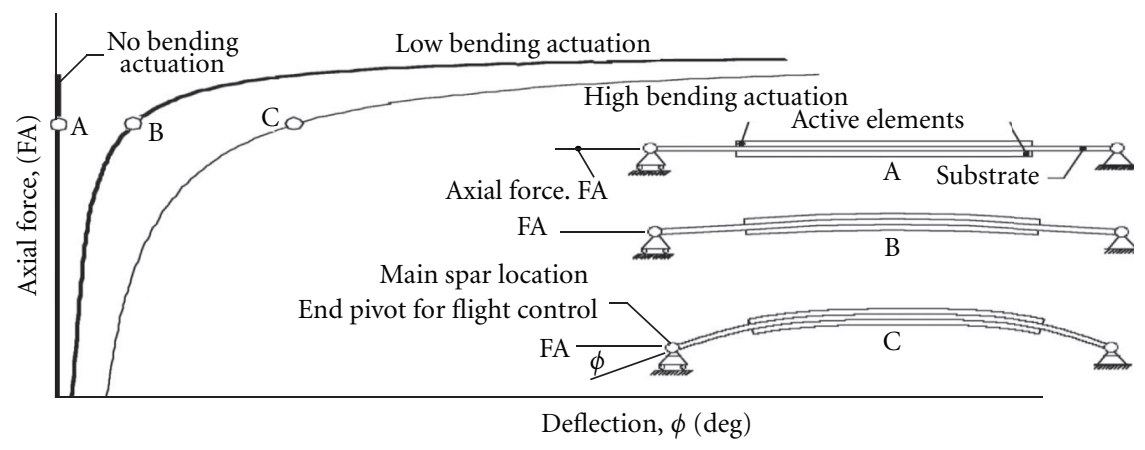

FIGURE 7: Basic arrangement of a linear postbuckled precompressed piezoelectric beam [46-54].

\section{PBP SSAR Root Actuator Modeling}

The overall design philosophy described above can be fairly easily implemented by simply balancing out forces. If one performs a simple accounting, it can be seen that actuator (a), passive laminate (1), aerodynamic (aero), propeller (prop), inertia, and damping moments about the feather axis should be nulled

$$
M_{\mathrm{a}}+M_{\mathrm{l}}+M_{\text {aero }}+M_{\text {prop }}+M_{\text {inertia }}+M_{\text {damping }}=0 .
$$

3.1. Actuator Modeling. If one considers the first two terms above, they relate to the laminate. By using a simple linear classical laminated plate theory (CLPT) model, the overall behavior of the symmetrical actuator can be seen in $[26,27]$. The techniques of [56] capture the moment balance, considering forces external (ex) to the laminate:

$$
\left\{\begin{array}{l}
N \\
M
\end{array}\right\}_{\mathrm{ex}}+\left\{\begin{array}{l}
N \\
M
\end{array}\right\}_{a}+\left\{\begin{array}{l}
N \\
M
\end{array}\right\}_{t}=\left[\begin{array}{ll}
A & B \\
B & D
\end{array}\right]_{1}\left\{\begin{array}{l}
\varepsilon \\
k
\end{array}\right\}_{1} .
$$

By expanding (2), the exact structure of the stiffness matrices above can be seen, considering external forces and moments represented by a simple vector 


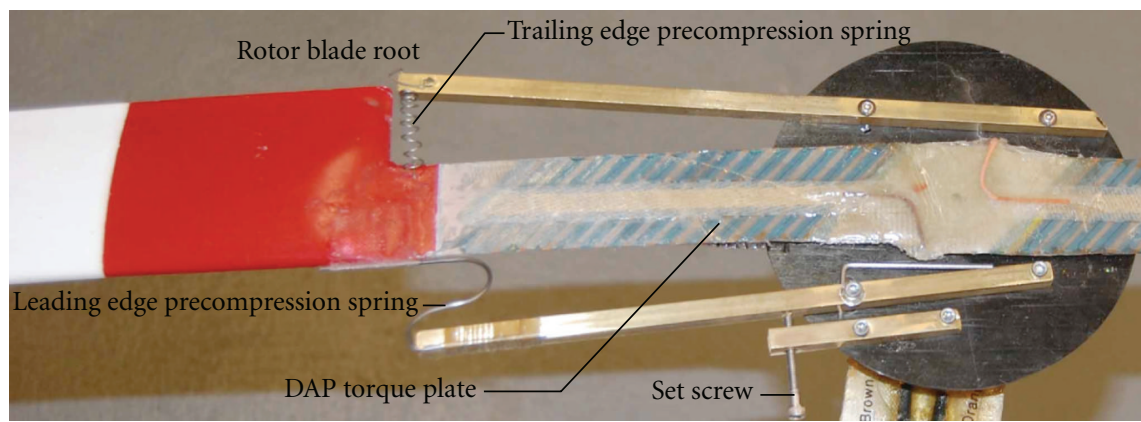

FIGURE 8: Retrofitted SSAR assembly with PBP feather (Pitch) stiffness-nulling springs.
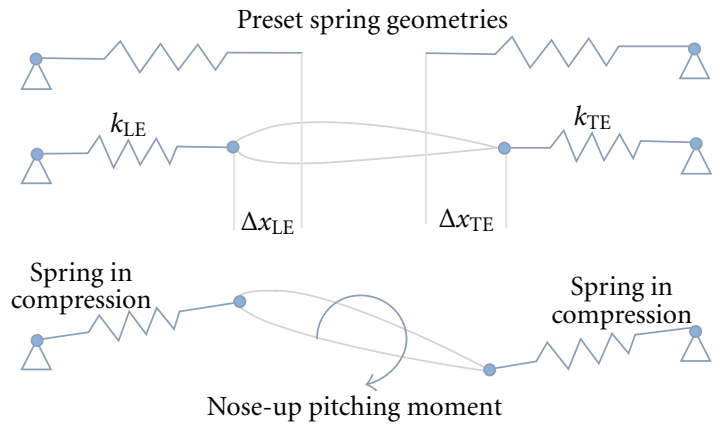

FIGURE 9: Destabilizing compression spring arrangement.

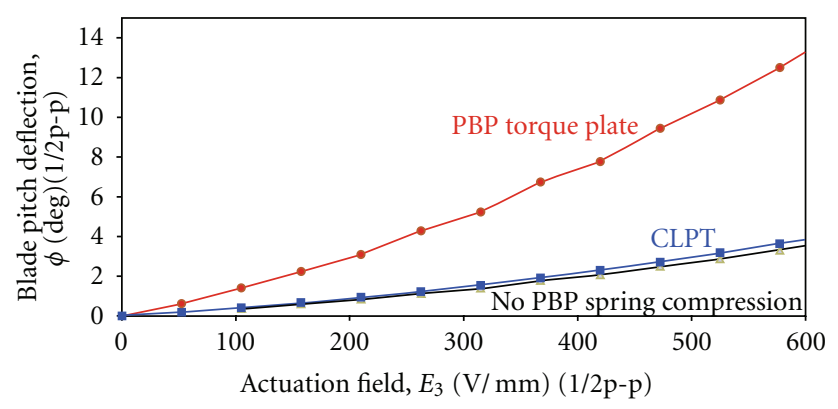

FIGURE 10: Blade pitch results with and without PBP spring compression.

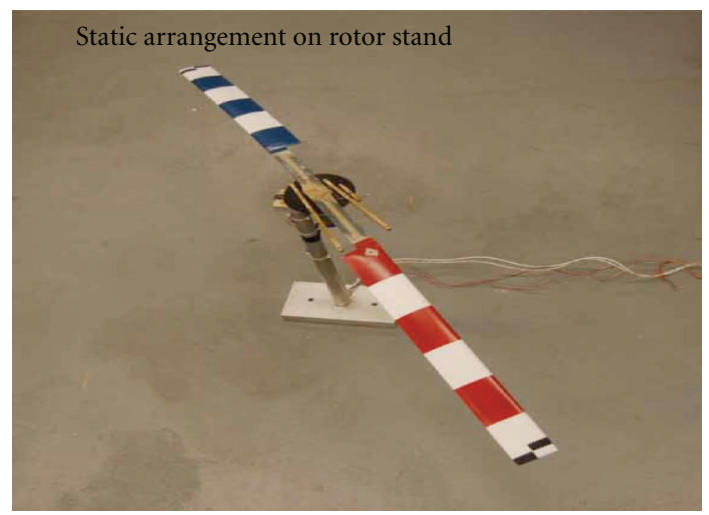

(a)

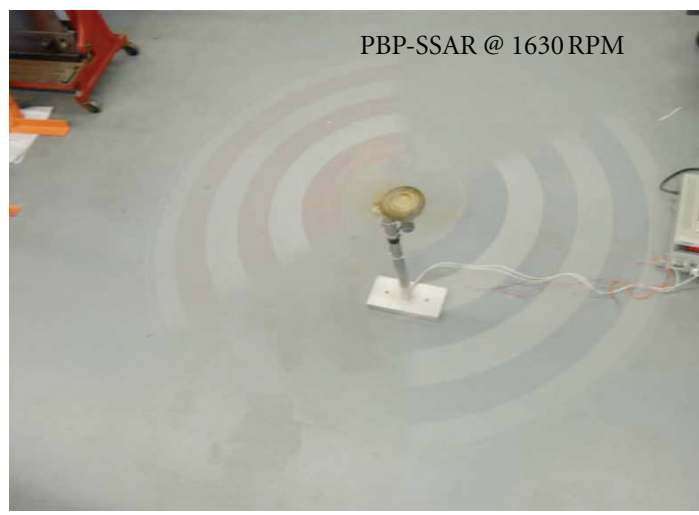

(b)

FIGURE 11: Solid state adaptive rotor on whirl-stand. 


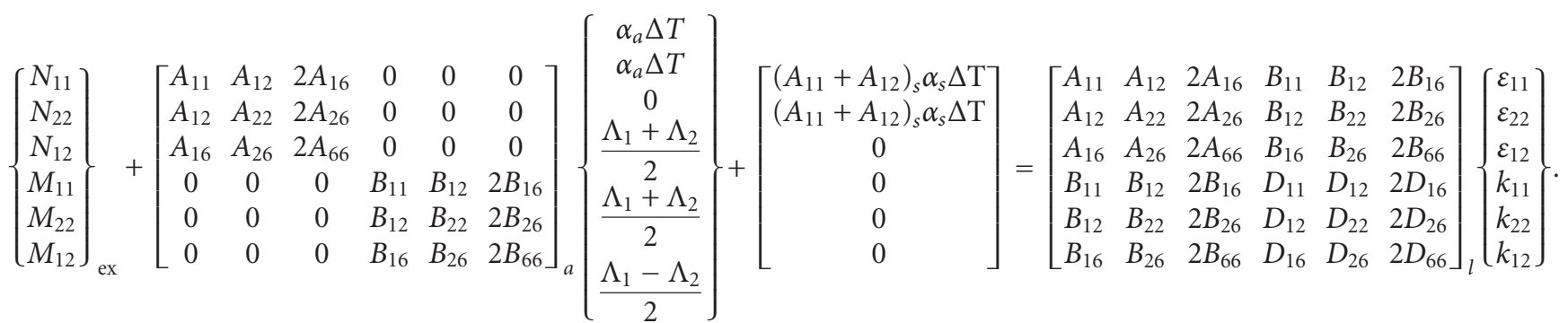

Considering a laminate constrained in curvature by high centripetal forces, the laminate twist can be solved as

$$
k_{12}=\frac{\left(E_{L}\left(1-v_{\mathrm{TL}}\right) \Lambda_{1}-E_{T}\left(1-v_{\mathrm{LT}}\right) \Lambda_{2}\right)\left(\left(t_{s}+2 t_{b}\right) t_{a}+t_{a}^{2}\right)}{\left(E_{s} t_{s}^{3}\left(1-v_{\mathrm{LT}} v_{\mathrm{TL}}\right)\right) /\left(6\left(1-v_{s}\right)\right)+\left(E_{L}+E_{T}-2 E_{L} v_{\mathrm{TL}}\right)\left(\left(\left(\left(t_{s}+2 t_{b}\right)^{2} t_{a}\right) / 2\right)+\left(t_{s}+t_{b}\right) t_{a}^{2}+\left(2 t_{a}^{3} / 3\right)\right)} .
$$

The actuator moment which can be applied by full hard-over pitch commands considering a bending-constrained laminate is shown in

$$
M_{a}=\frac{E_{L a}-E_{T a}}{4\left(1-v_{\mathrm{LT}} v_{\mathrm{TL}}\right)}\left(t_{s} t_{a}+t_{a}^{2}\right) W_{a} \Lambda .
$$

3.2. External Moments. If one examines the aerodynamic moments, then a simple offset between integrated centers of pressure, elastic axis, and line of centers of gravity can be seen:

$$
M_{\text {aero }}=\frac{1}{2} \rho \Omega^{2} R_{s p}^{2} C_{s p} B_{s p}\left(x_{c g}-x_{c p}\right) c_{l \alpha} \emptyset .
$$

Of course, the easy (and logical) design decision is simply to collocate the c.g., c.p. and e.a. so as to null those moments. One set of moments which require a bit of orthogonal design stems from propeller moments:

$$
M_{\text {prop }}=-m_{s p} \Omega^{2} r_{g}^{2} \varnothing .
$$

From (6) and (7) it is easy to see that aerodynamic and propeller moments are both proportional to blade pitch angle, ø. Through proper design, it is possible to balance out these two terms by judiciously prescribing the distance between the c.g. and c.p. Of course this is actually a comparatively dangerous move as the system can become dynamically unstable. In the interest of safety, the blade static margin will be set to zero or slightly positive.

\section{Rotor Fabrication, Testing, and Results}

Because the geometry of the $122 \mathrm{~cm}$ rotor model, its fabrication methods and materials are described in $[26,27]$, the reader is simply referred to those documents. The modified rotor, equipped with destabilization springs is shown in

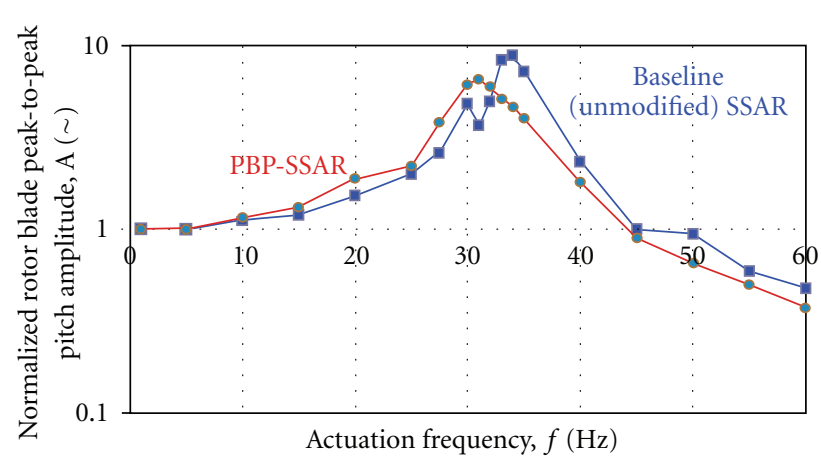

FIGURE 12: Dynamic response of SSAR and PBP-SSAR Systems.

Figure 8. Two series of tests were conducted: static bench tests and dynamic whirl-stand testing. Laser reflection techniques were employed to measure blade pitch deflections. Quasistatic excitation voltages were passed through the rotor hub at $1 \mathrm{~Hz}$. From Figure 10 it can be seen that both the laminated plate theory and the raw piezoelectric performance line up well (as shown in $[26,27]$ ). As the spring compression levels were increased, deflection levels were seen to grow and grow till the edge of structural stability was reached. Figure 10 shows the results from that "edge." By employing the practical experience and modeling techniques of [46-52], it can be seen that amplification ratios (AR) on the order of 3.53.8 are most generally achieved by bidirectional piezoelectric control actuation. Accordingly, the measured AR of 3.8 is seen to be an excellent achievement for the world's first torsionally amplified low-net passive stiffness piezoelectric actuator. It should be noted that the amplification ratio of 3.8 is essentially constant over the entire range of deflections commanded and measured.

In addition to amplification of static deflections, the thrust coefficient manipulation levels were also increased 
dramatically. Figure 11 shows the rotor undergoing whirlstand testing, demonstrating thrust coefficient manipulation levels 3.8 times higher than measured in the baseline SSAR laid out 15 years ago.

The dynamic testing showed an interesting trend: a slight reduction in both natural frequency and bandwidth, but maintenance of a high resonance peak as well as good frequency response. Figure 12 shows the dynamic response of the rotor system. The corner frequency of the unmodified SSAR blades and actuators was approximately $63 \mathrm{~Hz}$, while the low-net passive stiffness PBP incarnation of the system achieved a corner frequency of $53 \mathrm{~Hz}$.

\section{Conclusions and Recommendations}

It can be concluded that zero-net passive stiffness structural modification techniques can be successfully applied to torque-plate-driven rotors. Such successful application leads to dramatically higher deflections with no adverse effects on moment-generation capabilities, indicating higher total work levels available from such a Postbuckled Precompressed (PBP) Solid State Adaptive Rotor (SSAR) design. Pitch deflection levels were shown to be magnified by up to 3.8 times in static bench tests while thrust coefficient manipulation levels increased 2.8-fold during whirl-stand testing. Dynamic testing showed a reduction in corner frequency from 63 to $53 \mathrm{~Hz}$ by the use of PBP techniques, which represent 3.8 and $3.2 / \mathrm{rev}$, respectively.

Given the continued success of the SSAR design, it is recommended that such techniques be implemented in larger scale rotors and flying UAVs. The tremendous promise of this technique has the ability to make feasible now what was deemed "infeasible" many years ago.

\section{Acknowledgment}

The authors would like to acknowledge the University of Kansas Transportation Research Institute (TRI) for providing vital funding and support without which this research would not have been possible.

\section{References}

[1] E. F. Crawley and J. de Luis, "Use of piezoelectric actuators as elements of intelligent structures," AIAA Journal, vol. 25, no. 10, pp. 1373-1385, 1987.

[2] E. F. Crawley, K. B. Lazarus, and D. J. Warkentin, "Embedded actuation and processing in intelligent materials," in Proceedings of the 2nd international Workshop on Composite Materials and Structures for Rotorcraft, Troy, New York, NY, USA, September 1989.

[3] E. F. Crawley and E. H. Anderson, "Detailed models of piezoceramic actuation of beams," in Proceedings of the 30th Structures, Structural Dynamics and Materials Conference, Mobile, Ala, USA, April 1989.

[4] S. M. Ehlers and T. A. Weisshaar, "Effect of material properties on static aeroelastic control," in Proceedings of the 33rd SDM Conference, Dallas, Tex, USA, April 1992.

[5] V. Giurgiutiu, Z. Chaudhry, and C. Rogers, "Energy-based comparison of solid state actuators," Center for Intelligent
Material Systems and Structures Report No. CIMSS 95-101, Virginia Polytechnic Institute and State University, Blacksburg, Va, USA, 1995.

[6] R. L. Spangler and S. R. Hall, "Piezoelectric actuators for helicopter rotor control," in Proceedings of the 31st AIAA/ ASME/ASCE/AHS/ASC Structures, Structural Dynamics and Materials Conference, pp. 1589-1599, April 1990.

[7] C. Walz and I. Chopra, "Design, fabrication, and testing of a helicopter rotor model with smart trailing edge flaps," in Proceedings of the AIAA/ASME/ASCE/AHS/ASC 35th Structures, Structural Dynamics, and Materials Conference, Adaptive Structures Forum, pp. 298-319, Hilton Head, SC, USA, April 1994.

[8] O. Ben-Zeev and I. Chopra, "Continued development of a helicopter rotor model employing smart trailing-edge flaps for vibration suppression," in The International Society for Optical Engineering, vol. 2443 of Proceedings of SPIE, pp. 2-19, February 1995.

[9] F. K. Straub and D. J. Merkley, "Design of a smart material actuator for rotor control," in The International Society for Optical Engineering, vol. 2443 of Proceedings of SPIE, pp. 89104, San Diego, Ca, USA, February 1995.

[10] F. K. Straub and R. J. King, "Application of smart materials to control of a helicopter rotor," in Symposium on Smart Structures and Materials, Proceedings of SPIE, San Diego, Ca, USA, February 1996.

[11] F. K. Straub, M. A. Ealey, and L. M. Schetky, "Application of smart materials to helicopter rotor active control," in Smart Structures and Materials 1997: Industrial and Commercial Applications of Smart Structures Technologies, vol. 3044 of Proceedings of SPIE, San Diego, Ca, USA, March 1997.

[12] F. K. Straub, "Development of a full scale smart rotor system," in Proceedings of the 8th ARO Workshop on Aeroelasticity of Rotorcraft Systems, Penn State University, October 1999.

[13] N. A. Koratkar and I. Chopra, "Analysis and testing of a Machscaled helicopter rotor in hover with piezoelectric benderactuated trailing-edge flaps," in The International Society for Optical Engineering, vol. 3329 of Proceedings of SPIE, pp. 321332, San Diego, Ca, USA, March 1998.

[14] T. Lee and I. Chopra, "Design and static testing of a trailingedge flap actuator with piezostacks for a rotor blade," in Smart Structures and Materials 1998: Smart Structures and Integrated Systems, vol. 3329 of Proceedings of SPIE, pp. 321-332, San Diego, Ca, USA, February 1998.

[15] F. K. Straub, "Development of a full scale smart rotor system," in Proceedings of the 8th ARO Workshop on Aeroelasticity of Rotorcraft Systems, Penn State University, October 1999.

[16] N. A. Koratkar and Chopra, "Hover testing of a Machscaled rotor with piezoelectric bender actuated trailing-edge flaps," in Smart Structures and Materials: Smart Structures and Integrated Systems, N. W. Wereley, Ed., vol. 3985 of Proceedings of SPIE, Newport Beach, Ca, USA, March 2000.

[17] T. Lee and I. Chopra, "Development of a smart trailing-edge flap actuator with multi-stage stroke amplifier for a rotor blade," in Smart Structures and Materials: Smart Structures and Integrated Systems, N. W. Wereley, Ed., vol. 3985 of Proceedings of SPIE, pp. 11-25, Newport Beach, Ca, USA, March 2000.

[18] Anon., "Future Helicopters Get SMART," Science Daily, March 2009.

[19] D. K. Kennedy, F. K. Straub, L. M. Schetky, Z. Chaudhry, and R. Roznoy, "Development of a SMA actuator for in-flight rotor blade tracking," in Smart Structures and Materials 2000: Smart Swactures and Integrated Systems, vol. 3985 of Proceedings of SPIE, pp. 62-75, Newport Beach, Ca, USA, 2000. 
[20] R. M. Barrett, "Method and Apparatus for Structural Actuation and Sensing in a Desired Direction," U. S. Patent 5,440,193, Invention Disclosure: November, 1989.

[21] R. M. Barrett, "Intelligent rotor blade actuation through directionally attached piezoelectric crystals," in Proceedings of the Proceedings of 46th American Helicopter Society National Conference and Forum, Washington, DC, USA, May 1990.

[22] R. Barrett, Active rotor blade and structures development using directionally attached piezoelectric crystals, M.S. thesis, The University of Maryland, College Park, Md, USA, 1990.

[23] P. C. Chen and I. Chopra, "Hover testing of a smart rotor with induced-strain actuation of blade twist," in Proceedings of the 36th AIAA/ASME/ASCE/AHS/ASC Structures, Structural Dynamics, and Materials Conference and AIAA/ASME Adaptive Structures Forum, vol. 5, pp. 2836-2853, New Orleans, La, USA, April 1995.

[24] M. L. Wilbur, W. K. Wilkie, W. T. Yeager Jr. et al., "Hover testing of a NASA APL/MIT active twist rotor," in Proceedings of the 8th ARO Workshop on Aeroelasticity of Rotorcraft Systems, Penn State University, October 1999.

[25] E. Barkanov, S. Gluhih, and A. Kovalov, "Optimal design of the active twist for helicopter rotor blades with C-spar," Mechanics of Advanced Materials and Structures, vol. 15, no. 3-4, pp. 325334, 2008.

[26] R. Barrett and G. Cook, "The solid state adaptive rotor, design, development and implications for future rotorcraft," in Proceedings of the AGARD Flight Vehicle Integration Panel Symposium on Advances in Rotorcraft Technology, Ottawa, Canada, May 1996.

[27] R. Barrett, P. Frye, and M. Schliesman, "Design, development and testing of a solid state adaptive rotor," in 1996 Symposium on Smart Materials, Structures, and MEMS, vol. 3321 of Proceedings of SPIE, pp. 424-435, Bangalore, India, December 1996.

[28] F. K. Straub, "A feasibility study of using smart materials for rotor control," in Proceedings of the 49th Annual Forum of the American Helicopter Society, St. Louis, M, USA, May1996.

[29] F. K. Straub and R. J. King, "Application of smart materials to control of a helicopter rotor," in Smart Structures and Materials 1996: Industrial and Commercial Applications of Smart Structures Technologies, vol. 2721 of Proceedings of SPIE, pp. 66-77, San Diego, Ca, USA, February 1996.

[30] F. K. Straub, M. A. Ealey, and L. M. Schetky, "Application of smart materials to helicopter rotor active control," in Smart Structures and Materials 1997: Industrial and Commercial Applications of Smart Structures Technologies, Proceedings of SPIE, pp. 99-113, San Diego, Ca, USA, March 1997.

[31] F. K. Straub and D. J. Merkley, "Design of a smart material actuator for rotor control," in Smart Structures and Materials 1995: Smart Structures and Integrated Systems, vol. 2443 of Proceedings of SPIE, pp. 89-104, San Diego, Ca, USA, 1995.

[32] R. Barrett, "Adaptive aerostructures: the first decade of flight on uninhabited aerial vehicles," in Smart Structures and Materials 2004: Industrial and Commercial Applications of Smart Structures Technologies, Proceedings of SPIE, pp. 190201, San Diego, Ca, USA, March 2004.

[33] G. Lee, "Design and testing of the kolibri vertical take-off and landing micro aerial vehicle," Final Report for the Department of Defense CounterDrug Technology Office, November 1997.

[34] R. Barrett, "Wind tunnel report on the LuMAV rotary-wing micro aerial vehicle," Final Program Report for Lutronix Corporation for the DARPA Micro Aerial Vehicle Program, November 1999.
[35] R. Barrett and N. Howard, "Adaptive aerostructures for subscale aircraft," in Proceedings of the 20th Southeastern Conference on Theoretical and Applied Mechanics, Pine Mountain, Ga, USA, April 2000.

[36] R. Barrett and G. Lee, "Design criteria, aircraft design, fabrication and testing of sub-canopy and urban microaerial vehicles," in Proceedings of the AIAA/AHS International Powered Lift Conference, Alexandria, Va, USA, November 2000.

[37] R. Barrett, "Convertible Vertical Take-Off and Landing Miniature Aerial Vehicle," US Patent 6,502,787, 2002.

[38] G. A. Lesieutre and C. L. Davis, "Can a coupling coefficient of a piezoelectric device be higher than those of its active material?" Journal of Intelligent Material Systems and Structures, vol. 8, no. 10, pp. 859-867, 1997.

[39] G. A. Lesieutre and C. L. Davis, "Transfer Having a Coupling Coefficient Higher than its Active Material," US Patent 6,236,143, May 2001.

[40] M. R. Schultz and M. W. Hyer, "Snap-through of unsymmetric cross-ply laminates using piezoceramic actuators," Journal of Intelligent Material Systems and Structures, vol. 14, no. 12, pp. 795-814, 2003.

[41] M. R. Schultz, Use of piezoelectric actuators to effect snapthrough behavior of unsymmetric composite laminates, Ph.D. Dissertation, Engineering Science and Mechanics, Virginia Polytechnic Institute and State University, Blacksburg, Va, USA, 2003.

[42] M. R. Schultz and M. W. Hyer, "A morphing concept based on unsymmetric composite laminates and piezoceramic MFC actuators," in Proceedings of the 45th AIAA/ASME/ASCE/AHS/ASC Structures, Structural Dynamics and Materials Conference, pp. 3192-3204, Springs, San Diego, Ca, USA, April 2004.

[43] G. Giannopoulos, J. Monreal, and J. VanTomme, "High displacement nonlinear asymmetrically designed piezoelectric actuators," in Proceedings of the Active and Passive Smart Structures and Integrated Systems Conference, San Diego, Ca, USA, March 2006.

[44] J. Monreal, G. Giannopoulos, and J. VanTomme, "Analysis, construction and testing of a large displacement bistable piezoelectric actuator," in Proceedings of the Active and Passive Smart Structures and Integrated Systems Conference, San Diego, Ca, USA, March 2007.

[45] C. Maurini, J. Pouget, and S. Vidoli, "Bistable buckled beam: modelling and piezoelectric actuation," in Proceedings of the 3rd International Conference on Smart Materials, Structures and Systems - Smart Materials and Micro/Nanosystems (CIMTEC '08), vol. 54, pp. 281-286, September 2008.

[46] R. Barrett and P. Tiso, "PBP adaptive actuator device and embodiments," International Patent Application number PCT/NL2005/000054, via Technische Universiteit Delft, The Netherlands, 2005.

[47] R. Vos, R. Barrett, L. Krakers, and M. Van Tooren, "PostBuckled Precompressed (PBP) piezoelectric actuators for UAV flight control," in Smart Structures and Materials 2006: Smart Structures and Integrated Systems, San Diego, Ca, USA, March 2006.

[48] R. De Breuker, P. Tisot, R. Vos, and R. Barrett, "Nonlinear semi-analytical modeling of Post-Buckled Precompressed (PBP) piezoelectric actuators for UAV flight control," in Proceedings of the 47th AIAA/ASME/ASCE/AHS/ASC Structures, Structural Dynamics and Materials Conference, pp. 2461-2473, May 2006.

[49] R. Barrett, R. McMurtry, R. Vos, P. Tiso, and R. De Breuker, "Post-buckled precompressed piezoelectric flight 
control actuator design, development and demonstration," Smart Materials and Structures, vol. 15, no. 5, pp. 1323-1331, 2006.

[50] R. Vos, R. De Breuker, R. Barrett, and P. Tiso, "Morphing wing flight control via postbuckled precompressed piezoelectric actuators," Journal of Aircraft, vol. 44, no. 4, pp. 1060-1068, 2007.

[51] R. Vos, R. Barrett, R. D. Breuker, and P. Tiso, "Post-buckled precompressed elements: a new class of control actuators for morphing wing UAVs," Smart Materials and Structures, vol. 16, no. 3, pp. 919-926, 2007.

[52] R. Barrett, R. Vos, and R. De Breuker, "Post-Buckled Precompressed (PBP) subsonic micro flight control actuators and surfaces," in Active and Passive Smart Structures and Integrated Systems 2007, Proceedings of SPIE, San Diego, Ca, USA, March 2007.

[53] R. Vos and R. Barrett, "Dynamic elastic axis shifting: an important enhancement of postbuckled precompressed (PBP) actuators," in Proceedings of the 48th AIAA/ASME/ASCE/AHS/ASC Structures, Structural Dynamics, and Materials Conference, pp. 47-60, April 2007.

[54] R. Vos and R. Barrett, "Post-buckled precompressed techniques in adaptive aerostructures: an overview," Journal of Mechanical Design, vol. 132, no. 3, Article ID 031004, 11 pages, 2010.

[55] R. Barrett, "Hypermaneuverability and visual cloaking; new adaptive aerostructures technologies for uninhabited aerial vehicles (UAVs)," in Proceedings of the Bristol International Unmanned Air Vehicle Systems (UAVS) Conference, Bristol, UK, April 2008.

[56] R. M. Jones, "Micromechanical behavior of a lamina," in Mechanics of Composite Materials, Hemisphere, New York, NY, USA, 1975. 

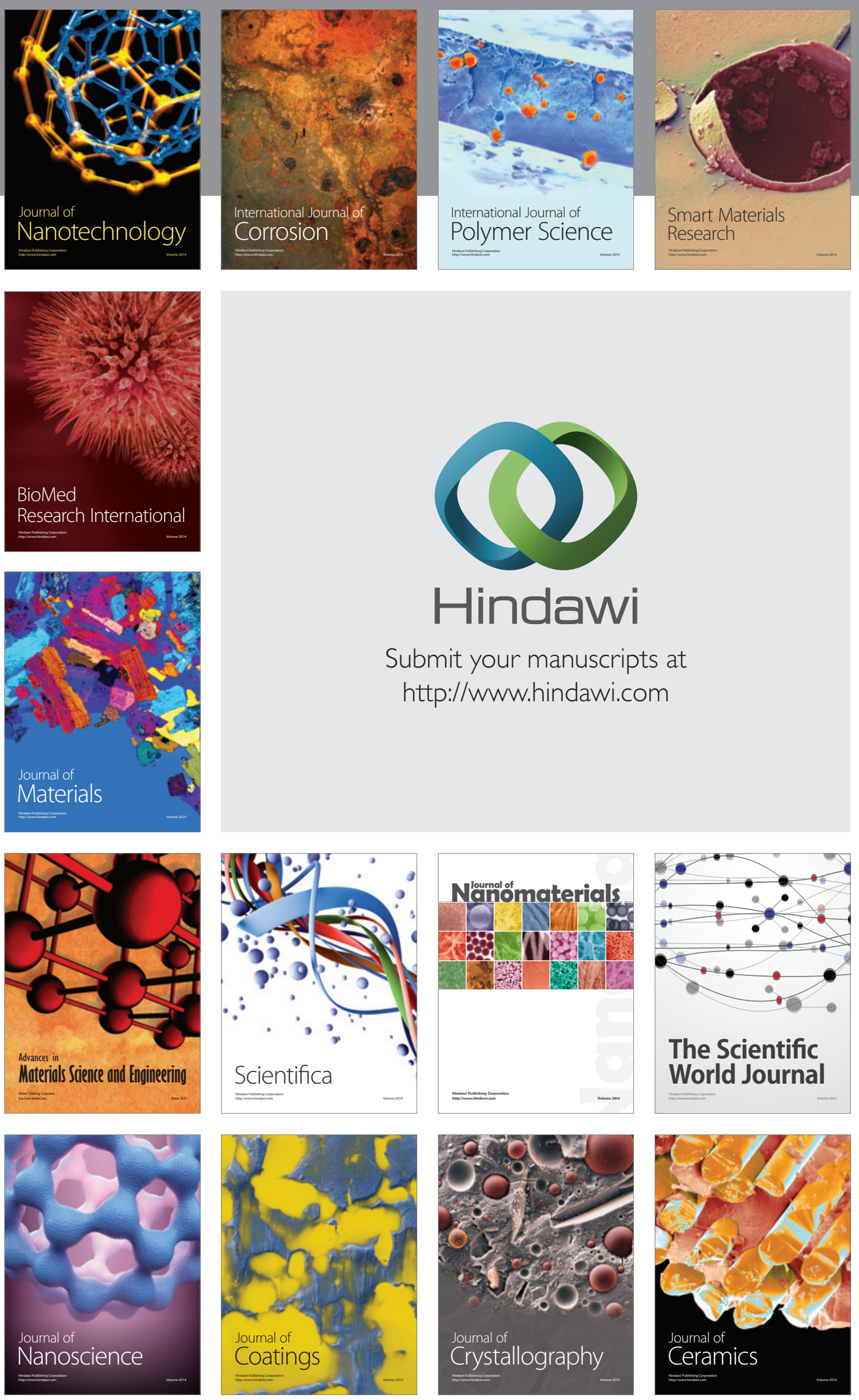

The Scientific World Journal

Submit your manuscripts at

http://www.hindawi.com

\section{World Journal}

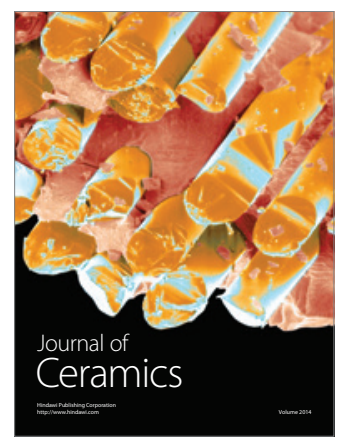

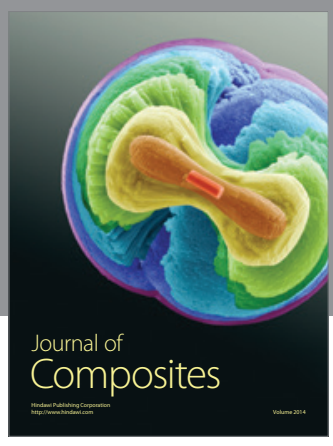
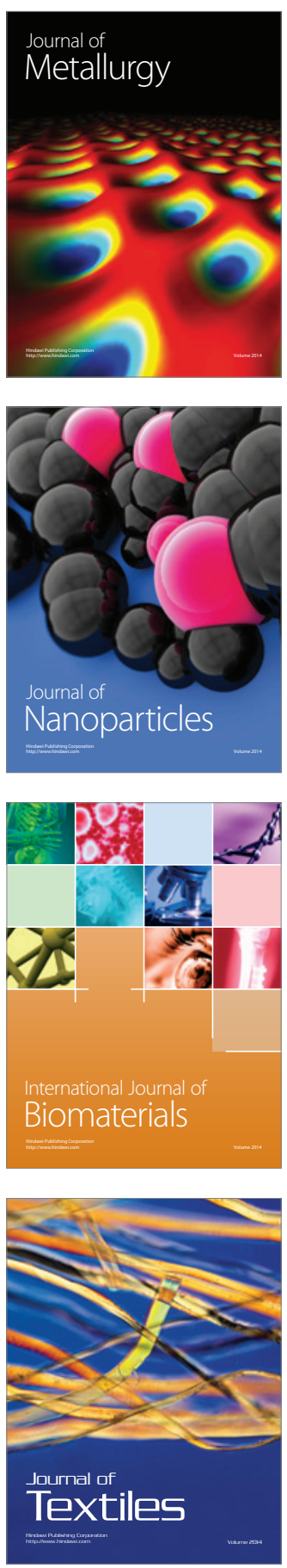